\title{
Formação inicial do professor de educação física reflexivo: tomando consciência de sua função social
}

https://doi.org/10.11606/issn.1981-4690.v35inespp15-22

\author{
Alan Barbosa Correa Ciriaco**** \\ Juliana Maia Garcia*
}

*Faculdade Lusófona,

Cotia, SP, Brasil.

**Faculdade Capital

Federal, Taboão da

Serra, SP, Brasil.

\section{Resumo}

0 objetivo deste estudo foi revisar e analisar criticamente a estruturação da literatura, publicada em periódicos científicos nacionais e internacionais, em torno da formação de licenciados em Educação Física. Para este fim adotou-se a revisão crítica da literatura, baseada na análise interpretativa de estudos de síntese e análise do objeto de estudo. Após a análise crítica das obras selecionadas, consideramos que, apesar da existência de diferentes metodologias de formação docente, a viabilização de um projeto que preconiza a reflexão, depende de políticas públicas e iniciativas privadas comprometidas com esse fim, incluindo desde a tomada de consciência da função individual até a coletiva, caracterizando dessa forma, mais do que a formação de professores, sistemas educacionais reflexivos. Para tanto, é indispensável que sejam realizadas pesquisas complementares multidisciplinares.

PAlaVRAs-ChaVe: Formação de formadores; Formação de licenciados em Educação Física; Formação do professor reflexivo; Formação de educadores.

\section{Introdução}

Muito se questiona sobre a qualidade do ensino básico nas escolas brasileiras, mais especificamente na cidade de São Paulo. Isso ocorre nas diferentes disciplinas que compóe a grade curricular escolar, inclusive na Educação Física. Nesse contexto, são raras as situações ou os ambientes escolares que consideram o professor de Educação Física como partícipe, parte importante no que se refere à formação integral do indivíduo. Situação inversamente proporcional é observada no mesmo contexto quando a área de atuação do profissional de Educação Física é a da saúde ${ }^{1}$. Entretanto, o que está aqui em questão não é a valorização da área da saúde versus a desvalorização da educaçáo no Brasil. O que se propõe evidenciar é a discussão sobre a dicotomia existente na atuação do profissional de Educação Física que hora atuando em um contexto é arbitrariamente desvalorizado, hora, em outro, não.

$\mathrm{O}$ que nos move a aprofundar os estudos neste tema é a necessidade de refletir sobre a formação do professor de Educação Física, no sentido de pensar, repensar e refletir sobre a sua função social, ou em outras palavras, a formaçáo de um professor reflexivo.

Segundo Betti e Zuliani ${ }^{2}$ e Darido ${ }^{3}$, em nossa atividade docente é comum nos depararmos com casos de alunos e alunas que desde que ingressaram à escola até a conclusão do ensino médio, não conseguem relatar o que aprenderam nas aulas de Educação Física, com dificuldade em atribuir um significado à disciplina além do prazer e da liberdade.

Para AlarCáo ${ }^{4}$, a escola deve ter como principal missão a formação/preparação de cidadãos que participam efetivamente do mundo em que vivem, portanto, a Educação Física, a partir de uma sistematização que leve em consideração os indivíduos que fazem parte do processo e seus respectivos mundos, deve contribuir para tanto.

Um dos objetos de estudo da Educação Física escolar é o lazer, porém, em virtude da falta de entendimento sobre sua função na escola, é comum que ocorram aulas de recreação que pouco contribuem para a formação integral do indivíduo e para a transcendência do que foi construído e aprendido para além da escola ${ }^{5}$.

Notamos que quando a atividade física não está relacionada à diversão, parte dos alunos, quase sempre a maioria, acredita que a Educação Física ensina a jogar algum esporte. Entretanto, podemos notar que apenas uma pequena parte destes alunos conseguem de fato jogar algum esporte de maneira efetiva, ou seja, sabendo qual sua função dentro do jogo, e mais, qual será a 
contribuição desta prática para sua formação, física, ética e social. Faz-se necessário citar que, segundo TuBINo ${ }^{6}$, o esporte é um fenômeno sociocultural e multifacetado, pois de acordo com o método empregado, podemos ter diversos resultados que podem contribuir, ou não, para a formação integral do indivíduo. Para isso, é necessário pensar o que, quando e como o esporte será empregado no processo de ensino-aprendizagem, para que não ocorra uma confusão entre as dimensóes sociais do esporte e para que, ao invés de contribuir para a formaçáo integral do indivíduo, promova a alienação e exclusão de seus praticantes.

No que diz respeito à prática docente, geralmente as estratégias aplicadas não favorecem as aprendizagens supracitadas. Nota-se a inexistência de uma sequência pedagógica nas diferentes faixas etárias, fazendo com que ocorra uma reprodução nas práticas escolares, corroborando com uma ideia de simples repetição ${ }^{7}$. O aprofundamento das aprendizagens nas diferentes dimensões do conteúdo, neste caso, dá lugar à execução de

\section{Método}

Adotou-se os desígnios da revisão crítica da literatura, baseada na análise interpretativa de estudos de síntese e análise do objeto de estudo. Ao objetivar a revisão crítica direcionada a iniciar uma discussão em torno da formação do educador reflexivo, foi realizado um levantamento bibliográfico de artigos e livros publicados nacionalmente e internacionalmente como fontes analíticas.

Para a busca dos estudos publicados foram utilizadas as bases de dados SciELO, Revista Brasileira de Educaçáo Física e Esportes, Revista Mackenzie de Educação Física e Esporte e acervo pessoal de livros. A consulta foi realizada no mês de novembro de 2018, utilizando os seguintes descritores e palavras-chave, na língua portuguesa: formação de formadores, formação inicial, formação de licenciados em educação física, formação do sequências de exercícios que obviamente náo contribuirão para a formação integral do cidadão.

A partir do apresentado, náo podemos desvincular esse fato à formação de professores. Seria um equívoco acreditar que um educador só inicia seu processo de profissionalização na universidade, visto que é necessário considerar todos os conhecimentos aprendidos, desde educação básica, no crescimento do indivíduo como ser ou agente social ${ }^{1-8}$.

Porém, na universidade é o momento em que o futuro professor de Educaçáo Física tem contato com todas as especificidades de sua área e principalmente, com o processo de iniciaçáo ao entendimento do seu papel social.

Este estudo se compromete em iniciar uma discussão em torno da formação do educador reflexivo dentre os profissionais de Educaçáo Física, capaz, conjuntamente com educadores de outras áreas de atuação, promover a formação integral de cidadãos autônomos, críticos e transformadores de sua realidade.

professor reflexivo, formação de educadores. Optou-se por não delimitar temporalmente a busca. Assim, foi possível identificar a totalidade de bibliografia relacionada ao objeto em questão.

Primeiramente, foram lidos os títulos e os resumos. Em caso de dúvida sobre inclusão ou exclusão, os textos foram lidos na íntegra, em um segundo momento. Os critérios de inclusão foram pesquisas publicadas nas bases de dados pré-estabelecidas que abordassem a formação do educador. Foram excluídas as pesquisas que não abordavam de forma objetiva a formação do educador e suas competências.

Depois de identificados os estudos e registros que atendiam ao objetivo desta revisão crítica, estes foram sintetizados e analisados para a construçáo do desenvolvimento.

\section{Desenvolvimento e discussão}

\section{Modelos e estratégias de formação}

Tomemos como exemplo alguns fatos sobre a formação docente em Portugal, que se apresenta

em constante evolução, na tentativa de reformular seus sistemas educacionais. Tal qual Portugal, 
o Brasil passa por um processo semelhante no que se refere às necessidades de políticas públicas efetivas para o ensino superior.

Apresentaremos a seguir as problemáticas levantadas por $\mathrm{NóvOA}^{9}$, que acabaram contribuindo para a discussão e reformulação da formação de educadores em Portugal: confusão entre formar e formar-se; desenvolvimento do profissional estimulado de forma individual e náo individual/ coletiva; formação não direcionada a uma perspectiva critico-reflexiva que favorecesse a autonomia e a participação efetiva do indivíduo em formação; ausência de reflexão crítica para a construção ou reconstrução de uma identidade pessoal e profissional; falta de conhecimento na ação pedagógica; falta de reflexão durante a ação pedagógica e carência na diversificação dos modelos e das práticas de formação com o saber pedagógico e cientifico.

A necessidade de analisar e repensar a formação de educadores também foi abordada por ZEICHNER ${ }^{10}$, que apresentou alguns paradigmas na formação de professores, os quais são descritos a seguir:

Paradigma comportamentalista: se desenvolve a partir de uma dimensão tecnicista do ensino; a formação tende a restringir-se a um conjunto de técnicas; o professor visto como um simples executor de leis e tarefas.

Paradigma Personalista: os programas são elaborados a partir das necessidades dos professores; conhecimentos e competências não estão prédefinidos, elas são construídas durante o processo, embora tenha como objetivo a conformidade dos docentes com um determinado modelo de maturidade psicológica.

Paradigma tradicional-artesanal: aprendizagem pela tentativa e erro; ocorre pela ótica do modelo clássico de mestre-aprendiz; os futuros docentes são vistos como receptadores passivos.

Frente a tais reflexôes, várias propostas de reformulação em relação à formação de professores vêm sendo desenvolvidas. De modo geral, a formaçáo de professores tem como referencial os modelos organizacionais. Com isso, segundo ZeICHNER ${ }^{10}$, tende-se a ignorar as implicaçôes filosóficas e políticas da formaçáo e consequentemente os diversos contextos sociais e educativos. $\mathrm{O}$ autor apresenta alguns modelos de formação:

Formação integrada: considera os componentes científicos e pedagógicos na formação. Modelo técnico que valoriza tanto a licenciatura quanto a pesquisa.

Formação sequencial: é uma variante da formação integrada. Neste caso a formação cientifica se dá de forma separada da formação pedagógica, embora esta seja dada na sequência da formação pedagógica.

Formação dual: neste modelo, a formação científica e a formação pedagógica são entendidas como duas formaçôes distintas, podendo com isto ocorrer em momentos muito diferentes.

Formação em exercício: a formação é feita nas próprias escolas, possibilitando uma articulação entre a teoria e a prática.

Formação em serviço: é uma proposta que se originou a partir da formação em exercício. A formação é realizada em uma instituição de ensino superior.

Atualmente as instituiçóes de formação de educadores vêm se inclinando às propostas de $S_{\text {CHÖON }}{ }^{11}$ e ZeICHNeR ${ }^{10}$, que acreditam que a formação do futuro profissional deverá incluir a reflexão a partir de situações práticas reais, corroborando com GADOTTI ${ }^{12}$, que comenta sobre a ineficácia da reflexão crítica se não houver um estreito vínculo com a prática.

Podemos notar que na atuaçáo de professores de Educação Física, os avanços neste processo se deram apenas nas açóes relacionadas ao planejamento, com grande distanciamento em relação às práticas pedagógicas que, na maioria das vezes, não ajusta os diferentes estímulos devido à falta de uma avaliação precisa e coerente, possibilitando ações futuras mais adequadas ao perfil apresentado pelos alunos e alunas.

Para um avanço efetivo na discussão e reformulação da formação de educadores é necessário que ocorra intervençôes em vários campos da sociedade que vão além do discurso. ZeIchNeR ${ }^{10}$ propõe inovações, que devem ser entendidas como desafios da formação docente, como desenvolvimento de programas temáticos de formação de professores; desenvolvimento de um currículo prático associado com os cursos específicos; produção de conhecimento sobre a escola e as vivências comunitárias; desenvolvimento de práticas centradas na investigação e nas práticas reflexivas; melhorias na qualidade da supervisão da prática, incluindo a supervisáo com o apoio dos colegas; criação de escolas clínicas e escolas de desenvolvimento profissional, visando maior envolvimento, comprometimento profissional e compreensão de ideia de prática como uma aprendizagem cognitiva.

Perrenoud ${ }^{13}$ também contribui para os avanços na formação do professor no que se referem à prática reflexiva apresentando algumas competências ligadas às transformaçóes do ofício do professor: organizar e estimular situaçóes de aprendizagem; gerenciar a progressão das aprendizagens; conceber e fazer evoluir dispositivos de diferenciação; envolver os alunos em 
suas aprendizagens e em seu trabalho; trabalhar em equipe; participar da gestão da escola; informar e envolver os pais; utilizar as novas tecnologias; enfrentar os deveres e os dilemas éticos da profissão e gerenciar sua própria formaçáo continuada.

A pouca ênfase dada às disciplinas como didática ou prática de ensino, assim como o próprio demérito ao momento de formação em campo nos estágios acadêmicos supervisionados obrigatórios, dentre outros fatores, resultam no que NóvoA ${ }^{14}$ chamou de formaçáo que hipervaloriza o discurso em detrimento da prática. Para o autor, há quatro elementos básicos que comprometem a qualificação prática dos professores: excesso de retórica política e de propaganda sobre práticas não concretizadas em detrimento de políticas públicas que efetivamente favoreçam o aperfeiçoamento da educação nacional; excesso de linguagens dos especialistas com aprimoramento do discurso docente, que abastece a máquina mercadológica sem de fato melhorar a formação de educadores; excesso de discurso científico educacional contrariamente relacionado à pobreza das práticas pedagógicas; valorização, em tese, do papel social do professor na educação, que não necessariamente se reflete em melhorias nas condiçóes de trabalho e no alcance de resultados significativos.

ZeIChNeR ${ }^{10}$ também se refere ao excesso de discurso científico educacional contraditoriamente associado à pobreza das práticas pedagógicas como um dos grandes desafios da educação moderna: qualificar os professores para darem aulas, além de falarem sobre dar aulas. O que se pretende dizer é que os dois fenômenos corroboram para que cada vez mais os professores saibam falar sobre educação, ainda que não saibam o que fazer sobre ela.

O contexto atual na formaçáo de professores no Brasil, em praticamente todos os cursos de licenciatura, sinaliza para uma dinâmica que pouco atende às novas demandas educacionais, aos processos de dinamização do ensino e aos modernos meios tecnológicos disponíveis. Tais cursos priorizam em seus currículos conteúdos de ordem teórica, teorias de desenvolvimento e mecanismos de preenchimento de documentos burocráticos muitas vezes indispensáveis aos diferentes sistemas de ensino, mas que pouco ou nada contribuem para que os professores adquiram, ainda no período de graduação, alguma competência prática de como ensinar. Tal fenômeno vem sofrendo grande influência também devido à grande oferta de cursos de Ensino a Distância - EAD.

Muitas mudanças ocorreram na formação de educadores nos últimos anos. Apesar de existirem várias propostas em relação à formação de professores, notamos que a prática ainda se encontra muito distante do que sugere os especialistas. Acreditamos que se faz necessário um investimento profundo nas práticas pedagógicas com o intuito de viabilizar estas teorias de maneira contextualizada e reflexiva, caso contrário, contribuiremos cada vez mais para a reprodução sistemática e alienada da educaçáo no ensino superior.

\section{Formaçáo do professor de educaçáo física: entre a bola e a educaçáo}

Ao iniciarmos um debate sobre a Educação Física, notamos que de modo geral, a formação de professores desta área, quase sempre, perpassa por diferentes situaçóes de acordo com diversas visóes, no que se refere ao comportamento humano nos aspectos motor, cognitivo e social, refletindo sua complexidade. A partir disso, faz-se necessário buscarmos em sua origem os primeiros passos da construção da Educação Física no Brasil, pois isso afeta de maneira significativa nas práticas apresentadas atualmente tanto nas escolas quanto nas universidades ou centros de formaçáo de professores.

Segundo Gimenez ${ }^{15}$ e Ciriaco ${ }^{16}$, a Educação Física sofre uma grande influência do militarismo e do higienismo, pois as primeiras práticas sistematizadas desta área de atuação geralmente estão diretamente ligadas ao desenvolvimento da aptidão física e ao processo de execução de um conjunto de técnicas típicas das modalidades esportivas. Isso não deveria ser um problema, caso não ocorresse paralelamente uma espécie de alienação e indução ao simples "aprender a fazer". Consequentemente, as práticas de formação de professores seguiam métodos tecnicistas, afirmando que um bom professor de Educação Física era aquele que sabia fazer bem o que gostaria que seus alunos aprendessem, sendo um bom exemplo desse fenômeno a apariçáo de diversos ex-atletas atuando em escolas, carregando consigo valores hegemônicos como comentam Hobsbawm $^{17}$, Bourdieu ${ }^{18}$, Norbert Elias ${ }^{19}$ e Tubino ${ }^{6}$. Não queremos dizer que o conhecimento técnico e específico não é importante, no entanto é necessário levar em consideraçáo outros aspectos além do movimento. Entretanto, são comuns professores universitários que ainda adotam métodos de avaliação que medem o desempenho esportivo de seus graduandos, como se isso fosse suficiente para que futuros profissionais da educaçáo consigam lidar com as demandas sociais que invariavelmente são vividas por alunas e alunos pela primeira vez dentro 
da escola, tais como exclusão, violências, intolerância à diversidade e a falta de oportunidades efetivas em relação ao conhecimento.

Além da visão tecnicista surge ainda, de acordo com Gimenez ${ }^{15}$, uma grande preocupação em incluir no currículo da formação de professores de Educação Física conhecimentos mais humanísticos, que comumente eram estudados por outras áreas do conhecimento, com o objetivo de enxergar os alunos e alunas não apenas como um amontoado de carne e osso, capacitando-os para adotar um comportamento que considere o indivíduo de maneira global. A visão supracitada corrobora com os ideais da Teoria da Motricidade Humana, desenvolvida por SÉRGIO ${ }^{20}$. Tal condição elevaria o profissional de Educação Física a uma condição de efetivo educador, não sendo suficiente saber fazer, mas também saber ensinar.

Vale à pena ressaltar que isso pode ser fruto da crise de identidade vivida pela educação física, pois existem diferentes opinióes sobre sua função: saúde, esporte, cultura do movimento, motricidade humana...; não que seja necessário que todos pensem da mesma maneira, porém desde o ingresso até o egresso, o graduando não passa por um processo de formação que seja capaz de garantir uma prática reflexiva no que se refere às quais contribuiçôes que ele pode dar à sociedade em suas diferentes possibilidades de prática.

SérGio ${ }^{20}$ explica que a Universidade deve influenciar o modo de uma nação ser e estar no mundo, em que o natural cede lugar ao cultural. No entanto, para que haja esta mudança, faz-se necessário uma atitude crítica e racional perante rotinas, privilégios, superstiçôes e dogmas instaurados nas instituiçôes universitárias, promovendo emancipaçáo dos graduandos no que se refere à instrumentalização do saber e do fazer, ideia esta apresentada também por Gimenez ${ }^{15}$ e Piccolo ${ }^{21}$.

Sendo assim, a partir de uma reflexão do papel das instituiçóes responsáveis pela formação inicial do profissional de Educação Física, é importante que ocorra a promoção de um processo que busque a compreensão da função social desses futuros profissionais de educação.

\section{A formaçáo do professor de educaçáo física reflexivo: uma visão individual}

No que se refere à atuação docente no ensino superior, é comum que os professores apresentem uma atuação baseada em teorias reconhecidas internacionalmente, pois sabe-se que quanto maior o acúmulo de conhecimento deste profissional maior é a representação da sua autoridade. Se adotarmos um comportamento tradicional e reacionário, talvez esta afirmativa esteja de fato correta, mas, se partirmos do princípio de que nem sempre uma teoria pode ser viabilizada antes de haver uma contextualização, respeitando valores morais e educacionais do grupo em questão, iremos perceber que a universidade, salvo exceções, promove uma formação voltada ao controle, indo de encontro à formaçấo do indivíduo autônomo. É claro que a escolha do método de trabalho dependerá de qual processo de formação o professor do ensino superior participou em sua formação inicial e continuada, pois é notável que só fazemos aquilo que sabemos fazer. Para PerRenoud ${ }^{13}$, uma prática metódica, regular e instrumentalizada só pode ser adquirida por meio de um treinamento intensivo e deliberado. Celante ${ }^{1}$ considera que o processo de formaçáo docente começa desde a condição discente e que as habilidades necessárias para refletir devem ser aprendias, sendo, portanto, passíveis de serem aprendidas.

Para DeweY ${ }^{22}$, uma prática pedagógica que se aproxime da reflexão e da criticidade, deve ser iniciada a partir de fenômenos reais apresentados pelo grupo envolvido no processo, que comumente manifesta-se a partir de "situações problema". Para isso é necessário que o "mediador do processo", antes de sistematizar sua práxis, leve em consideração alguns estágios como a análise da dificuldade (problema), as alternativas de solução do problema, a experimentação de várias soluçóes até que o teste mental aprove uma delas e a ação como prova final para a solução proposta, que deve ser verificada de maneira científica.

Além disso, quando iniciamos um debate sobre a prática reflexiva crítica individual, partimos do pressuposto que o professor deve a todo o momento refletir sobre a sua prática antes, durante e depois de sua realização, ou seja, na avaliaçáo diagnóstica e no planejamento, na execução e na avaliação dos resultados, seguido de ajustes futuros de acordo com ShÖON ${ }^{1}$ e MeLlo ${ }^{23 .}$

Podemos esperar que uma prática reflexiva individual, segundo Perrenoud ${ }^{13}$, compense a superficialidade da formação profissional; favoreça a acumulaçáo de saberes de experiência; propicie evolução rumo à profissionalização; prepare para assumir uma responsabilidade política e ética; permita enfrentar a crescente complexidade das tarefas; ajude a vivenciar um ofício impossível; ofereça os meios necessários para trabalhar sobre si mesmo; estimule a enfrentar a irredutível alteridade 
do aprendiz; aumente as capacidades de inovação e possibilite a cooperação entre os colegas.

A partir disso, é de fundamental importância que as competências individuais possam contribuir para uma atuaçáo coletiva reflexiva.

\section{A formação do professor de educaçáo física reflexivo: uma visão coletiva}

Em todas as áreas do conhecimento sabemos que náo é nada fácil promover um processo de formaçáo que oriente o egresso para práticas reflexivas. Entretanto, este desafio torna-se muito mais difícil quando o corpo docente náo corrobora dos mesmos valores morais no que se refere à educação. Utilizando parte da citação apresentada anteriormente, PERRENoud ${ }^{13}$ comenta que a formaçáo profissional deve aumentar a cooperação entre os colegas, pois como sabemos, a universidade muitas vezes pode ser chamada como o "templo das vaidades". Embora de maneira alguma tenhamos o objetivo de depreciar ou subjugar os profissionais que fazem parte desse grupo tão seleto da área da educação, quando buscamos uma prática reflexiva, os interesses individuais não podem se sobrepor aos coletivos.

Segundo LibÂNeO ${ }^{24}$ e Alarcão ${ }^{4}$, uma prática reflexiva deve estar vinculada à uma escola reflexiva, pois o bom professor é aquele que permite um processo de coeducação que promova infinitas possibilidades de construção coletiva, responsabilidade compartilhada, liderança e desenvolvimento contínuo, para que, posteriormente, ocorra um processo de reflexão e reconstrução do processo de ensino/aprendizagem, com profunda comunicação entre a teoria e a prática, facilitando desse modo, um processo educacional significativo.

Voltamos a comentar sobre a função social das universidades, referente à formação de professores, pois o que percebemos é que a grade curricular contribui para a esportivização exacerbada não dando espaço para disciplinas que estimulem uma reflexáo a fim de perceber a real função da escola, ou seja, a formaçáo integral dos alunos e alunas rumo à autonomia. Para Durkheim ${ }^{25}$, a escola, em todos os níveis, deveria preparar os jovens, por meio dos preceitos básicos, para a convivência em sociedade.

Segundo SÉRGIO ${ }^{20}$, faz-se necessário que o professor universitário, para a promoção de uma formação reflexiva, se desprenda de tradiçóes e paradigmas para uma possível educaçáo capaz de humanizar o desenvolvimento e desenvolver humanizando, pois não podemos contribuir para uma educação física que não considera o sujeito, que segue as manobras de manipulação em massa, mais interessada em adestrar os alunos e alunas ou apenas divertir, distanciando-se do real objetivo da educação.

Para Durkheim ${ }^{25}$, o objetivo da educação permanece indeterminado, bem como a própria educação, pois ela se submete à arbitrariedade individual. Contudo, a formação de um professor de Educação Física reflexivo pode ser determinante para a compreensão de que o processo de educação ocorre de maneira coletiva a partir de inúmeras formas de cooperação de diversas áreas de conhecimento, sendo, portanto, fruto do coletivo.

Corroborando com o ideal de educação defendido por Durkhein ${ }^{25}$, Zeichner ${ }^{10}$ contribui com a ideia de que as universidades não podem perder de vista a visão social de seu trabalho e devem levar em consideração que o professor reflexivo deve desenvolver, em seus alunos e alunas, a consciência da sociedade à qual pertencem. Adicionalmente, devem exigir de todos os seus membros, a compreensão de qual o grupo social específico (casta, classe, família, profissão) fazem parte. Ao estabelecer momentos em que os trabalhos sejam mais divididos entre os participantes, será ampliada a diversidade de aptidóes profissionais mais ricas e coerentes com a realidade que o espera, provocando em seus alunos e alunas a transformação do ser egoísta e antissocial em um ser capaz de levar uma vida moral e social harmoniosa, pois só somos o que somos porque vivemos em sociedade.

\section{Considerações finais}

Partindo do que nos motivou a iniciar este estudo, que foi discutir a formaçấo do professor de Educação Física, encontramos um campo potencialmente fértil para infinitas reflexôes relacionadas à função social do profissional supracitado.

No que se refere aos modelos e métodos para a formação do profissional em questão, percebe-se uma construção de um discurso bem elaborado, porém com muitas dificuldades na viabilização de ambientes que favoreçam a reflexão sobre a prática pedagógica, 
seja pela influência mercadológica ou pela falta de reflexão entre os formadores de educadores.

Em relação à tomada de consciência da função social do professor de Educação Física, seja individual ou coletiva, percebe-se que a dificuldade neste processo não ocorre apenas no que concerne a atuação profissional, mas também nas relaçôes no âmbito privado e público, considerando que a humanidade apresenta limitaçóes em evitar que os desejos/interesses individuais sobreponham o coletivo, sem o real entendimento da isonomia e isegoria, preconizados pela Constituição Federal Brasileira.

Portanto, para que ocorra a superaçáo dos impactos desse fenômeno, é necessário um envolvimento sobrenatural dos diferentes campos de nossa sociedade, sejam eles políticos, econômicos, educacionais e culturais, além de novos estudos comprometidos com a promoção de transformação social.

\begin{abstract}
Inicial formacion of physical education teacher reflexive: taking consciency of your social function

The aim of this study was to review and critically analyze the structuring of literature, published in national and international scientific journals, in concer of the training of graduates in Physical Education. To this end, a critical literature review was adopted, based on the interpretative analysis of synthesis studies and analysis of the object of study. After the critical analysis of the selected studies, we consider that, despite the existence of different teacher training methodologies, the feasibility of a project that advocates reflection depends on public policies and private initiatives committed to this end, including since the awareness of individual to collective function, thus characterizing, more than teacher education, reflective educational systems. Therefore, it is essential that complementary multidisciplinary research be carried out.
\end{abstract}

KEYWORDS: Training of trainers; Training of graduates in Physical Education; Training of reflective teacher; Educator training.

\title{
Referências
}

1. Celante AR. Notas sobre a pesquisa no cotidiano escolar acerca dos saberes na ação de professores de Educaçáo Física. In: Gimenez R, Souza MT, organizadores. Ensaios sobre contextos da formação profissional em Educação Física. Várzea Paulista, SP: Fontoura; 2011. p. 27-46.

2. Betti M, Zuliani LR. Educação física escolar: Uma proposta de diretrizes pedagógicas. Rev Mackenzie Educ Fís Esporte. 2002;1:73-81.

3. Darido SC. A educação física na escola e o processo de formação dos não praticantes de atividade física. Rev Bras Educ Fís Esp. 2004;18:61-80.

4. Alarcão I. Escola reflexiva e nova racionalidade. Porto Alegre: Artimed Editora; 2001.

5. Marcellino NC. A teoria sociológica da decisão e a ação comunitária como estratégias de planejamento em ação. In: Marcellino NC, Zingoni PE, Pinto LMSM, organizadores. Como fazer projetos de lazer: elaboração, execução e avaliação. Campinas: Papirus; 2007. p.83-172.

6. Tubino M. As dimensóes sociais do Esporte. São Paulo: Cortez: Autores Associados; 1992.

7. Santos BS. Para uma pedagogia do conflito. In: Freitas AL, Moraes SC, organizadores. Contra o desperdício da experiência. A pedagogia do conflito revisitada. Porto Alegre: Redes Editora Ltda; 2009. p. 15-40.

8. Geraldi CMG, Messias MGM, Guerra MDS. Refletindo com Zeichner: um encontro orientado por preocupaçóes políticas, teóricas e epistemológicas. In: Geraldi CMG, Fiorentini D, Pereira EM, organizadores. Cartografias do trabalho docente. Campinas: ALB; 2011. p.11-19.

9. Nóvoa A. Os professores e sua formação. Lisboa: D. Quixote; 1995.

10. Zeichner K. A formação reflexiva de professores: idéias e práticas. Lisboa: Educa; 1993.

11. Schön D. Educando o profissional reflexivo: um novo design para o ensino e a aprendizagem. Porto Alegre: Artes Médicas; 2000. 
12. Gadotti M. Perspectivas atuais da educação. Porto Alegre, Ed. Artes Médicas; 2000.

13. Perrenoud P. A prática reflexiva no ofício de professor: profissionalização e razão pedagógica. Porto Alegre: Artmed Editora; 2002.

14. Nóvoa A. Os professores na virada do milênio: do excesso dos discursos à pobreza das práticas. Educ Pesq.1999;25:11-20. Disponível em: https:/www.scielo.br/pdf/ep/v25n1/v25n1a02.pdf.

15. Gimenez R. Século XXI: conquistas e perspectivas na formação de professores de educação física. In: Gimenez R, Souza MT, organizadores. Ensaios sobre contextos da formação profissional em Educaçáo Física. Várzea Paulista, SP: Fontoura; 2011. p.73-82.

16. Ciriaco ABC. Por uma raça mais forte, sã e viril: a institucionalizaçáo da formaçáo de professores de educaçáo física no estado de São Paulo (1901 -1934) [dissertação]. São Paulo (SP): Pontifícia Universidade Católica de São Paulo - PUC - SP, História da Ciência; 2019.

17. Hobsbawm E. A era dos impérios: 1875-1914. Rio de Janeiro: Paz e Terra; 1988.

18. Bourdieu P. Como é possível ser esportivo? In: Bourdieu P. Questôes de Sociologia. Rio de Janeiro. Marco Zero; 1983. p.136-153.

19. Elias N. A gênese do desporto: um problema sociológico. In: Elias N, Dunning E. A busca da excitaçáo. Lisboa: Difel; 1992. p.187-221.

20. Sérgio M. Epistemologia da motricidade humana. Lisboa, Cruz-Quebrada: Ediçóes Faculdade de Motricidade Humana Universidade Técnica de Lisboa; 1996.

21. Piccolo VLN. A formaçáo de professores de Educaçáo Física: desafios e propostas. In: Gimenez R, De Souza MT, organizadores. Ensaios sobre contextos da formação profissional em Educaçáo Física. Várzea Paulista, SP: Fontoura; 2011. p.127-140.

22. Dewey J. Como pensamos. Barcelona: Paidós; 1989.

23. Mello GN. Formação inicial de professores para a educação básica: uma (re) visão radical. São Paulo Perspectiva. 2007;14: 98-110. Disponível em: https://www.scielo.br/pdf/spp/v14n1/9807.pdf. Acesso em: 01 dez 2020.

24. Libâneo JC. Adeus professor, adeus professora? São Paulo: Cortez; 1998.

25. Durkheim E. Educação e Sociologia. Tradução de Stephania Matousek. 3. ed. Petrópolis, RJ: Vozes (Coleção Textos Fundantes de Educação); 2012.

\begin{tabular}{r|r} 
ENDEREÇO & \\
Alan Barbosa Correa Ciriaco & \\
Faculdade Lusófona & Recebido: 10/ 12/2020 \\
Av. Nossa Senhora da Assunção, 722 & Aceito: 18/ 12/2020 \\
05359-001 - São Paulo - SP - Brasil & \\
E-mail: alan.ciriaco2@hotmail.com & \\
alanciriaco10@hotmail.com &
\end{tabular}

